\title{
South Asian children: contribution of meals and snacks towards nutrient intake
}

\author{
W. Husain ${ }^{1}$ and S. Khokhar ${ }^{1}$ \\ ${ }^{1}$ School of Food Science and Nutrition, University of Leeds, Leeds, LS2 9JT, UK
}

Childhood is the period of life when dietary habits are formed which are very likely to continue into adulthood. Recent studies suggest that childhood nutrition may be associated with the subsequent risk of developing coronary heart disease, type 2 diabetes, certain cancers and obesity in adult life ${ }^{(1)}$. In the case of South Asian children this becomes even more critical since South Asians are at high risk of developing nutrition-related diseases ${ }^{(2)}$. However, there is lack of information on dietary habits and intakes of these children. The aim of this study was to assess the energy distribution and macro- and micronutrient intakes of South Asian children (1 y-3 y) living in the UK throughout the day.

Ethical approval for this cross-sectional study was obtained from the University of Leeds. The children's parents $(n=123)$ completed 369 multiple pass 24-hour recalls on non-consecutive days, including one weekend. All foods were analysed using the latest available data on South Asian foods generated through Food Standard Agency and European Food Information Resource Network ${ }^{(3)}$. The WinDiets software was also used.

Mean energy intake of South Asian children was $1181.6 \mathrm{kcal} / \mathrm{day}$, with $14.5 \%$ of the energy obtained from protein, $47.2 \%$ from carbohydrate and $37.9 \%$ from fat. The daily distribution of energy intake throughout the day was $17.6 \%$ at breakfast, $18.1 \%$ at lunch, $17.4 \%$ at dinner, $40 \%$ from snacks and $6.6 \%$ from night feeding.
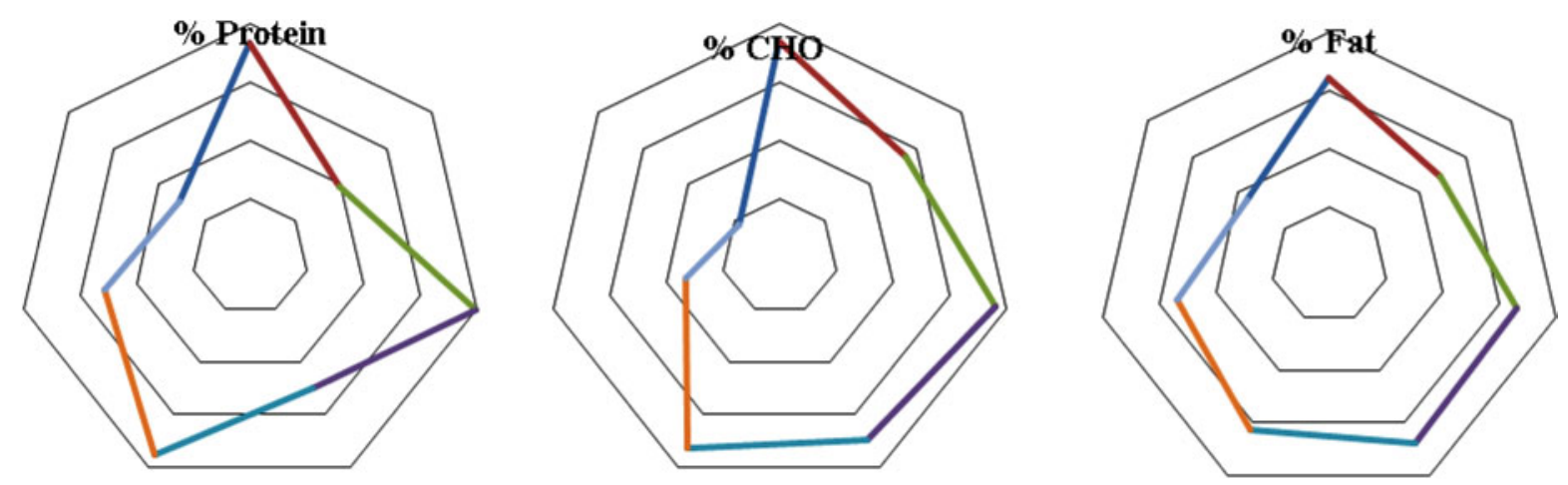

Table 1. Distribution of micronutrient intake through meals and snacks (consumers only)

\begin{tabular}{|c|c|c|c|c|c|c|c|}
\hline Nutrient & Breakfast & Snack 1 & Lunch & Snack 2 & Dinner & Snack 3 & *Other \\
\hline \%Iron & 30.3 & 9 & 18.2 & 10.6 & 21.2 & 6.1 & 4.5 \\
\hline \%Zinc & 21.2 & 9.6 & 17.3 & 11.5 & 17.3 & 13.5 & 9.6 \\
\hline$\%$ Calcium & 23.3 & 10.3 & 9.7 & 14.3 & 10.2 & 19.3 & 12.9 \\
\hline$\%$ Vitamin A & 17.5 & 12.5 & 12.6 & 13.5 & 13.7 & 14.6 & 15.6 \\
\hline \%Vitamin D & 18.75 & 12.5 & 12.5 & 12.5 & 12.5 & 6.25 & 25 \\
\hline \%Vitamin C & 12.5 & 20.0 & 15.2 & 21.6 & 12.7 & 8.5 & 9.5 \\
\hline
\end{tabular}

*Other: night feeding

It is concluded that the distribution of energy, macro- and micronutrient intakes across meals and snacks help to evaluate children's dietary pattern and habitual intake. The breakfast meal provided a higher level of nutrients than lunch or dinner. Night feeding (full fat cow milk) was found to be a common practice in this group and contributed to up to $25 \%$ of total vitamin D intake. Snacks provided the highest vitamin $\mathrm{C}$ intake which was mainly derived from fruit juices.

1. Lytle LA, Himes JH, Feldman H et al. (2001) Public Health Nutrition 5(2): 319-328.

2. Misra A \& Khurana L (2011) Int. J Obesity 35, 167-187.

3. European Food Information Resource Network (2010) WP2.3.2. Final Report on Ethnic Foods. Leeds: EuroFIR. 